\title{
Australians say yes to more research funding
}

\section{To the editor:}

The editorial "Turning the virtuous cycle"1 was timely indeed. Australian researchers are eagerly awaiting the delayed report Investment Review of Health and Medical Research by John Grant (chair of Biota) and the response of the Federal Government. The editorial referred to the strong community support for health research demonstrated in Research Australia's Health and Medical Research Opinion Poll 2002 (http://www.researchaustralia.org/files/ Research\%20Australia\%20public \%20opinion\%20polling\%20doc.pdf). The extraordinary support of the Australian community has been further corroborated in Research Australia's Public Opinion Poll 2003 (http://www.researchaustralia.org/ files/ResA $\% 20$ Health $\% 20 \& \% 20$ Medical $\% 20$ Research\%20Public\%20Opinion\%20Poll \%202003.pdf), released on 1 March 2004.

Research Australia is a national alliance of more than 100 member organizations promoting health and medical research in Australia. Research Australia commissioned ACNielsen, an independent marketing research company, to conduct the second annual public opinion poll in November 2003. A representative sample of the Australian adult population was interviewed by telephone 'omnibus' survey.
Australians recognize that health and medical research has already made a difference in their lives. Four of five Australians believe Australia is a world leader in health and medical research and want community investment increased. In 2000-2001, less than two cents in each health care dollar spent by the community went to health and medical research in Australia. The poll suggests that two thirds of the Australian population want to see this amount more than doubled, and in fact one third want to see it more than tripled. This would bring the proportional spending in line with the US, where approximately six cents in each health care dollar is spent on research (www. researchamerica.org).

When it comes to community priorities in Australia, health and education are clearly 'top of the mind' issues. Interestingly, our polling suggests that when 'health and medical research' is separated from 'hospitals and health care', it remains a top-three priority. Health and medical research was viewed as the most important cause for corporate giving; the second most important recipient for individual donations; and the third most important area for government expenditure, just behind 'hospitals and health care' and 'schools and universities.' The importance of this funding is considered to be ahead of funding for the environment, defense and community welfare (http://www.research australia.org/files/ResA\%20Health\%20\& $\% 20$ Medical\%20Research\%20Public\%20 Opinion\%20Poll\%202003.pdf).

Australians also send a clear message that they are prepared to give personally to medical research through donations; $88 \%$ are willing to pay an extra $\mathrm{A} \$ 1$ on each prescription medicine and even pay more tax for access to the latest treatments! Importantly, they see Australia as part of the global community: $85 \%$ believe Australian government-funded research efforts should address global health problems, not just Australian health issues.

Governments, philanthropists and corporate Australia should view these findings as compelling encouragement for increased investment to realize Australia's important contribution to global health research and development.

\section{Christine Bennett}

Chief Executive Officer, Research Australia, 20 Bridge Street, Sydney, NSW 2000, Australia. e-mail:christine.bennett@asx.com.au

1. Turning the virtuous cycle. Nat. Immunol. 5, 231 (2004). 